\title{
HEALTH ADVANTAGES OF BREAST FEEDING FOR INFANTS: A CRITICAL REVIEW
}

\author{
M. JANE HEINIG AND KATHRYN G. DEWEY \\ Department of Nutrition, University of California, Davis, CA 95616, USA
}

\section{CONTENTS}

\begin{tabular}{|c|c|c|c|c|c|c|c|c|c|c|c|c|}
\hline INTRODUCTION & . & & . & . & & . & & • & & & $\cdot$ & 89 \\
\hline METHODOLOGICAL ISSUES & $\cdot$ & & & . & . & . & & . & & & 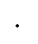 & 90 \\
\hline PHYSIOLOGICAL AND BEHAVI & OUR & $2 \mathrm{AL}$ & DEV & $\mathrm{EL}$ & OPA & EN & & . & . & & . & 91 \\
\hline PHYSIOLOGICAL DEVELOPMENT & & . & . & . & $\cdot$ & $\cdot$ & & . & 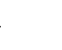 & & - & 91 \\
\hline BEHAVIOURAL DEVELOPMENT & & . & $\cdot$ & . & . & . & . & . & . & . & . & 92 \\
\hline BREAST FEEDING AND INFAN & $\mathrm{T} \mathrm{MC}$ & OR B & IDIT & $\Gamma Y$ & & . & . & . & & . & . & 3 \\
\hline MECHANISMS FOR THE ASSOCIAT & ION & BET & WEEN & N BR & EAs & & EDI & & $\mathrm{ANI}$ & & & \\
\hline INFANT MORBIDITY & . & & $\cdot$ & . & $\cdot$ & $\cdot$ & . & & & . & . & 3 \\
\hline ACUTE INFECTIOUS ILLNESS & . & . & . & . & . & . & & & & . & & 93 \\
\hline GASTROINTESTINAL DISEASES & . & . & . & . & . & . & . & & & . & & 4 \\
\hline NECROTIZING ENTEROCOLITIS & . & . & . & . & . & . & . & & & . & . & 95 \\
\hline RESPIRATORY DISEASES & . & . & . & . & . & . & . & & & . & & 96 \\
\hline OTITIS MEDIA & . & . & . & . & . & . & . & & & . & & 97 \\
\hline BACTERAEMIA AND MENINGITIS & & . & . & . & . & . & . & & & . & & 98 \\
\hline INFANT BOTULISM & . & . & . & . & . & . & . & & & . & & 98 \\
\hline URINARY TRACT INFECTION & . & . & . & . & . & . & . & & & . & $\cdot$ & 98 \\
\hline CHRONIC ILLNESS & . & . & . & . & . & . & · & & & . & . & 9 \\
\hline INSULIN-DEPENDENT DIABETES & MELL & LITU & & . & . & . & & & . & . & . & 99 \\
\hline CROHN'S DISEASE AND ULCERA & TIVE & $\mathrm{COL}$ & ITIS & · & . & $\cdot$ & & & . & . & . & 100 \\
\hline CHILDHOOD CANCER & . & ${ }^{\circ}$ & . & . & . & . & & & . & . & . & 101 \\
\hline ALLERGY & . & . & . & . & . & . & . & & . & . & . & 101 \\
\hline BREAST FEEDING AND INFAN & $\mathrm{T} \mathrm{MC}$ & ORT & ALIT & & . & . & . & & & . & . & 102 \\
\hline INFANT MORTALITY FROM ALL & CAUS & & . & & & . & . & & & . & . & 102 \\
\hline SUDDEN INFANT DEATH SYNDRC & $\mathrm{ME}$ & & . & . & . & . & . & & . & . & . & 102 \\
\hline CONCLUSIONS & & . & . & . & . & . & . & & . & . & & 103 \\
\hline REFERENCES & . & . & . & . & . & & . & & & . & & \\
\hline
\end{tabular}

\section{INTRODUCTION}

In the last two decades, an enormous amount of research has focused on the value of breast feeding for infants, mothers, and society as a whole. Human breast milk is recognized as the best source of nutrition for young infants and it is now known that many constituents of human milk play multiple roles in the promotion of infant health and development (Lawrence, $1994 \mathrm{~b}$ ). In addition, a number of non-nutritional benefits have been attributed to breast-feeding, including enhanced physiological and behavioural development and 
protection against various acute and chronic illnesses. However, not all of these claims have been universally accepted. Evidence that breast feeding improves the health status of infants is greatest under adverse circumstances where alternative feeding methods may be inadequate or hazardous. In developing countries, breast feeding saves the lives of millions of infants each year by improving nutritional status and reducing morbidity. However, results from studies in industrialized countries have been mixed. Many of these studies have been criticized for their methodological and analytical limitations (Sauls, 1979; Bauchner et al. 1986; Kramer, 1987). In this review, methodological issues relevant to breast feeding studies will be described and current research on the non-nutritional benefits of breast feeding for infants will be critically examined in the light of these issues. Because of space limitations, this review will not include discussions of the nutritional value of human milk or circumstances where breast feeding may be contraindicated (such as maternal HIV infection). These topics have been recently reviewed by others (Institute of Medicine, 1991; Ruff, 1994). The adequacy and beneficial effects of human milk for preterm and low birth-weight infants have also been subjects of recent reviews (Goldman et al. 1994; Lawrence, 1994a; Schanler, 1995). Therefore, the emphasis of this paper will be on potential health advantages for term infants. A subsequent review will focus on the health effects of breast feeding for mothers.

\section{METHODOLOGICAL ISSUES}

For ethical reasons, it is not possible randomly to assign infants to receive breast milk or infant formula. Therefore, researchers generally must rely on observational epidemiological studies to examine the relationships between infant feeding and subsequent outcomes. Ten years ago, Bauchner et al. (1986) described four methodological standards for evaluating studies of the relationship between infant feeding and infectious illness. Briefly, these criteria were: (1) avoidance of detection bias (i.e. use of a prospective study design with active surveillance of subjects); (2) adequate control for confounding variables; (3) clearly defined outcome events; and (4) a clear definition of what is meant by 'breast feeding'.

Although Bauchner et al. (1986) required that infant feeding groups be clearly defined, they did not specify what those definitions should be. In some studies, infants have been classified as 'breast fed' if they have received any amount of breast milk at any time in their lives. As a result, groups of 'breast fed' infants may include infants who were offered breast milk only once or twice in the hospital as well as those who were exclusively breast fed for 4-6 months. Comparable definitions of breast feeding practices are vital for comparisons across studies. According to the Interagency Group for Action on Breastfeeding (Labbok \& Krasovec, 1990), the term 'exclusive breastfeeding' is applicable only when the infant receives no other fluids or solids. In many research studies, infants are often classified as 'exclusively breast fed' if they receive less than what is considered a trivial amount of nutrients from other sources. However, depending on the environment, even non-nutritive fluids such as water and tea can have an effect on infant morbidity. Breast fed infants receiving other nutritive fluids and foods are commonly classified as 'partly breast fed', and are often lumped into one group despite the tremendous range in how these infants are fed, without regard for differences in feeding frequency and types of food offered. Infant feeding is a dynamic, complex process. Infants may move in and out of several feeding categories during the interval of interest, further complicating the definition of feeding mode.

In a review of the association between breast feeding and atopic disease, Kramer (1988) describes a set of 12 methodological standards that are more stringent than those described by Bauchner $e t$ al. (1986). Two of these refer to the need to select subjects with sufficient exclusivity and duration of breast feeding to examine adequately the hypothesis in 
question. Other criteria, in addition to those listed by Bauchner et al. (1986), include (a) non-reliance on prolonged maternal recall; (b) blind ascertainment of infant feeding history; (c) blind ascertainment of outcome; (d) information on the severity of outcome; (e) age at onset of outcome; (f) assessment of dose-response effect; (g) assessment of effect in children at high risk; and $(\mathrm{h})$ adequate statistical power.

In this review, we have selected studies (conducted primarily in industrialized countries) that meet at least three of the four criteria described by Bauchner et al. (1986). For rare outcomes such as chronic diseases (e.g. childhood lymphoma), it was necessary to relax the criterion for avoidance of detection bias, as prospective studies are not always feasible. Although it would have been ideal to screen studies using the criteria listed by Kramer (1988) as well, this would have drastically reduced the number of studies to be considered. However, within each of the sections below, greater attention is given to studies that provide information on the duration and/or exclusivity of breast feeding in the definition of feeding groups.

\section{PHYSIOLOGICAL AND BEHAVIOURAL DEVELOPMENT}

\section{PHYSIOLOGICAL DEVELOPMENT}

Human milk contains a variety of hormones and hormone-like substances. Evidence from animal studies indicates that many milk hormones and growth factors are absorbed into the neonatal circulation and have important physiological functions in the neonate (Polk, 1992; Grosvenor et al. 1993).

Several components of human milk contribute to gastrointestinal development and maturation (Yellis, 1995). In the laboratory, human milk was found to have growth promoting activity in cultured fetal intestinal cells (Ichiba et al. 1992). Growth promoting activity level was very high in colostrum and decreased gradually during lactation. Specific growth factors have been isolated and studied. For example, clinical studies have determined that epidermal growth factor in human milk is resistant to digestion and promotes the proliferation of intestinal mucosa (Koldovsky, 1994).

Metabolic differences between breast fed and formula fed infants have been reported in the literature. Butte and coworkers (1990) reported that sleeping metabolic rate and body temperature were lower in breast fed infants than in formula fed infants during the first months of life. Compared with formula fed infants, breast fed infants have slower rates of gastric filling (Lucas et al. 1981) and faster rates of gastric emptying (Cavell, 1981). Breast fed infants also differ from artificially fed infants in their hormonal response to feeds (Blackburn \& Loper, 1992). The short or long term consequences of these metabolic differences have yet to be determined.

Fatty acids in human milk may also play a role in infant development. One of these fatty acids, docosahexaenoic acid (DHA), has been the focus of several studies (Ponder et al. 1992; Bjerve et al. 1993; Carlson et al. 1993; Crawford, 1993; Makrides et al. 1993). DHA is highly concentrated in erythrocytes, brain and retinal tissues (Nettleton, 1993) and its concentration in erythrocytes and brain cortex is higher in breast fed than in other infants (Makrides et al. 1994). In preterm infants, DHA status is positively correlated with psychomotor and mental development indices (Bjerve et al. 1993). Improved retinal function (Uauy-Dagach \& Mena, 1995) and visual acuity (Carlson, 1989) have been reported in premature infants fed human milk compared to those fed infant formula. Full term breast fed infants have higher erythrocyte DHA levels and better visual function than infants who receive infant formula as their primary energy source (Birch et al. 1993; Makrides et al. 1993). Lanting and coworkers (1994) reported that, among children who had been born at term, exclusive breast feeding for at least 3 weeks was associated with 
fewer neurological abnormalities at 9 years of age after controlling for obstetric, perinatal, necnatal, neurological and social differences.

\section{BEHAVIOURAL DEVELOPMENT}

In several large studies, children who had been breast fed had a small but statistically significant advantage over those who had been artificially fed in scores attained on a variety of cognitive tests (Rodgers, 1978; Fergusson et al. 1982; Taylor \& Wadsworth, 1984; Morley et al. 1988; Morrow-Tlucak et al. 1988; Lucas et al. 1992; Rogan \& Gladen, 1993; Temboury et al. 1994). In studies of term infants (Rodgers, 1978; Fergusson et al. 1982; Taylor \& Wadsworth, 1984; Morrow-Tlucak et al. 1988; Rogan \& Gladen, 1993; Temboury et al. 1994), researchers have found differences of 2-9 points on cognitive tests after controlling for potential confounders such as socioeconomic status, parental education, family size, birth order, maternal age, maternal smoking and birth weight. Differences between groups were seen in children as early as I (Morrow-Tlucak et al. 1988) and as late as 15 years of age (Rodgers, 1978). Admittedly, these differences are subtle and their functional significance is unknown. Other factors which are not easily measured or controlled and are related to both mode of feeding and cognitive development may be responsible for these results.

Differences in cognitive scores associated with feeding mode have also been seen in preterm infants. In a multicentre study, Lucas and coworkers (Lucas et al. 1989, 1990, 1992, 1994) evaluated cognitive development among very low birth-weight $(<1850 \mathrm{~g})$ preterm infants. Mothers in the study were asked whether or not they wished to provide their own breast milk to their infants. If a mother chose not to provide her own milk, her infant was randomly assigned to be fed (via nasogastric tube) either banked human milk, a standard infant formula or a special preterm infant formula. If a mother decided to provide her own breast milk, her infant was randomly assigned to receive one of the diets above as needed to supplement her own milk. The diets were administered until the infant either left the hospital or reached $2000 \mathrm{~g}$. Developmental tests were conducted when the infants were 9 and 18 months of age (Lucas et al. 1984, 1989, 1990). Follow-up cognitive tests, including tests of IQ, were administered when the children reached 7 or 8 years of age (Lucas et al. 1992). Developmental tests administered in the first 12 months are not predictive of later development (Colombo, 1993). Therefore, results from testing at 9 months will not be discussed here. At 18 months, scores on tests of mental and psychomotor development were similar between infants who had received human milk and those who had received the special preterm formula. Infants who had received the standard formula had significantly lower scores than those who had received the preterm formula (Lucas et al. 1990, 1994). It is important to note that the banked milk used was mainly 'drip milk' which was very low in fat and energy compared with either the preterm formula (Lucas et al. 1990) or breast milk obtained from full expression of the breast (Lawrence, 1994b). Cognitive scores among children 7-8 years of age who had received their own mother's breast milk were higher than in those who had received only formula or banked human milk (Lucas et al. 1992). These differences remained significant after adjustment for maternal education and social class. Furthermore, in an analysis including only those infants who had received their own mother's milk, cognitive scores were positively related to the amount of milk their mothers were able to provide. The authors suggest that infants who receive breast milk may be at an advantage because human milk contains various factors that might affect brain growth or nervous system development.

Interpretation of the results of Lucas and colleagues is complicated by the fact that each paper concerns a different sample of their large study population and little descriptive 
information about each sample is provided. Furthermore, while the overall study included a randomized design, mothers self-selected whether or not to provide their own milk. The comparison made when the children were 7-8 years of age was not randomized. As a result, uncontrolled differences between groups may be responsible for differences in cognitive development. In this and many studies, maternal education serves as a surrogate for other variables such as child rearing practices and maternal IQ. However, Wright \& Deary (1992) point out that only a fraction of maternal IQ may be explained by differences in educational attainment and social class. To address this concern, Lucas et al. (1992) compared the cognitive scores between children who received their own mother's milk $v .17$ children whose mothers intended to provide their own milk but were not successful in doing so. The scores of these latter 17 children were similar to those of children whose mothers had chosen not to provide breast milk. While this finding is important, the small number of infants in this category limits its generalizability.

Taken as a whole, the results of studies on both term and preterm infants are remarkably consistent in showing that breast feeding is associated with enhanced cognitive development. Further research is needed to establish whether this is a causal relationship, and to elucidate the potential mechanisms involved. These mechanisms could include not only the influence of certain breast milk constituents on central nervous system development, but also behavioural aspects related to maternal-infant interaction during breast feeding.

\section{BREAST FEEDING AND INFANT MORBIDITY}

\section{MECHANISMS FOR THE ASSOCIATION BETWEEN BREAST FEEDING AND INFANT MORBIDITY}

In the past, differences in morbidity and mortality between breast fed and artificially fed infants were generally attributed to differences in exposure to pathogens introduced through contaminated foods or fluids. While important, this indirect protection is not the only means by which breast milk contributes to the health of the infant. It is now known that many constituents of human milk enhance the neonate's immune system. Nonnutritive constituents have been reported to provide direct protection against microbial pathogens, to modulate inflammatory processes, and to promote the growth and maturation of several organ systems (Goldman et al. 1994; Orlando, 1995).

Several recent reviews have described the complex system of antimicrobial factors that exists in human milk (Kunz \& Rudloff, 1993; Goldman et al. 1994; Orlando, 1995). These include (a) carbohydrates that inhibit binding of certain bacterial pathogens to epithelial cells; (b) nitrogen-containing sugars that promote growth of beneficial lactobacilli and bifidobacteria in the lower intestinal tract; (c) antibodies such as secretory IgA and serum $\operatorname{IgG}$, which prevent binding and proliferation of pathogens and may actively prime the newborn's immune system; (d) anti-inflammatory agents; (e) antioxidants; (f) white blood cells such as neutrophils and macrophages; (g) lactoferrin, an iron binding protein that inhibits proliferation of iron requiring bacteria; (h) lysozyme, an enzyme that attacks microbial pathogens; (i) antiviral lipids; and (j) antiprotozoan factors. The precise mechanisms of action of each of these factors are still being investigated.

\section{ACUTE INFECTIOUS ILLNESS}

In their review of breast feeding and acute infectious illness, Bauchner et al. (1986) included studies published between 1970 and 1984 . Very few of those studies met at least three of their four methodological standards, and even in the six that did there were other 
significant flaws that precluded definitive conclusions. The authors concluded that there was little evidence for a protective effect of breast feeding in industrialized countries. However, since that time there has been considerable additional research using more rigorous study designs. In the sections below on gastrointestinal diseases, respiratory infections and otitis media we restrict our review to studies conducted since that of Bauchner et al. Because their paper did not cover other types of infection, no such restriction was placed on the studies we include in the sections on necrotizing enterocolitis, bacteraemia and meningitis, infant botulism, and urinary tract infection.

\section{GASTROINTESTINAL DISEASES}

The evidence that breast feeding is protective against infectious disease is greatest for diarrhoeal illnesses. Under adverse conditions, breast feeding can protect infants from a deadly cycle that begins with recurrent diarrhoea and ends in death (Mitra \& Rabbani, 1995). In 1984, the World Health Organization published a review of 35 studies examining the relationship between breast feeding and diarrhoeal disease in developing countries (Feachem \& Koblinsky, 1984). Breast feeding was protective in $88 \%$ of those studies. Infants receiving no breast milk in the first months of life were 3.5-4.9 times more likely to suffer from diarrhoeal disease than infants who were exclusively breast fed. More recent studies have affirmed the protective effect of breast feeding against diarrhoeal diseases in developing countries (Brown et al. 1990; Huffman \& Combest, 1990; Popkin et al. 1990; de Zoysa et al. 1991; Mitra \& Rabbani, 1995) and against specific enteric pathogens such a rotavirus (Yolken et al. 1992; Clemens et al. 1993), Giardia lamblia (Morrow et al. 1992; Walterspiel et al. 1994), Shigella (Clemens et al. 1986; Ahmed et al. 1992) and Campylobacter (Nachamkin et al. 1994).

While the evidence from developing countries is conclusive, studies conducted in developed countries have produced conflicting results. In industrialized countries, studies have been carried out primarily in middle class populations where exposures to enteric pathogens are low. During the first year of life, reduced diarrhoeal illness among breast fed infants compared with formula fed infants has been reported in some (Duffy et al. 1986; Howie et al. 1990; van den Bogaard et al. 1991; Ruuska, 1992; Dewey et al. 1995) but not all (Rubin et al. 1990) of the recent studies meeting at least three of the four criteria described by Bauchner et al. (1986). Of these, only four provided adequate information on infant feeding practices (Duffy et al. 1986; Howie et al. 1990; Rubin et al. 1990; Dewey (') al. 1995).

Duffy et al. (1986) compared relative risk of gastroenteritis and rotavirus infection among 197 US infants who were exclusively breast fed with those who were mixed fed or formula fed. Feeding mode was classified at birth and again at 4 months of age. Among those exclusively breast fed for 4 months, there was a significant reduction in risk for allcauses gastroenteritis (relative risk $(\mathrm{RR})=0 \cdot 29 ; 95 \%$ confidence interval $(\mathrm{CI})=0 \cdot 24-0.83$ ) compared with those who were mixed fed or formula fed. Risk for rotavirus infection was similar between groups. However, of the 10 cases of rotavirus gastroenteritis among the breast fed infants, $90 \%$ were classified as mild, compared with only $36 \%$ of the 25 cases among bottle fed infants.

In a study of 750 pairs of mothers and infants in Scotland, Howie et al. (1990) compared rates of gastrointestinal illness among breast fed and bottle fed infants. Throughout the first year, infants breast fed for 13 weeks or more were found to have significantly less gastrointestinal illness than those who were bottle fed from birth. The protective effect of breast feeding extended beyond the period of breast feeding and was also associated with a reduction in the rate of hospitalization. 
In a large prospective study, monthly questionnaires were mailed to the parents of 500 Danish infants who had been interviewed in the hospital at the time of birth. The questionnaire included detailed questions on feeding practices and illnesses. After adjustment for confounding factors, no significant relationship was found between the type of feeding and the incidence of gastroenteritis (Rubin et al. 1990). However, the return rate of monthly questionnaires declined from $92 \%$ at 1 month to only $44 \%$ at 12 months. Feeding group categories included two mixed feeding groups identified as 'breast feeding $>$ formula feeding' and 'formula feeding $>$ breast feeding'. Since no attempt was made to assess breast milk intake and breast feeding mothers are unlikely to know how much breast milk their infants consume, it is unclear how this classification was made. For the bulk of the analyses, the mixed fed infants were grouped with the exclusively breast or bottle fed infants based on their predominant milk source. Therefore, in these analyses, both groups used for comparison included mixed fed infants.

In a study comparing matched groups of infants who were breast fed or formula fed until 12 months of age, Dewey et al. (1995) reported that the incidence of diarrhoeal illness among formula fed infants was approximately twice that of breast fed infants during the first year of life. This difference remained significant after controlling for day care use and number of siblings. Infants in the study were matched for characteristics such as birth weight, parental socioeconomic status, and maternal education.

\section{NECROTIZING ENTEROCOLITIS}

Necrotizing entercolitis (NEC) is the most common life threatening gastrointestinal disease seen in neonatal intensive care units (Kliegman \& Fanaroff, 1984). No single causative agent has been identified and little is known about the aetiology of the disease. Factors implicated in the aetiology of NEC include infectious agents (bacterial and viral), abnormal patterns of intestinal colonization, compromised immune response and an inflammatory response to feeds (Buescher, 1994). Studies in animals have shown that fresh human milk is protective against NEC (Buescher, 1994) but frozen human milk is not. However, earlier studies in human neonates found no protective effect of breast feeding (Kliegman, 1979; Moriarty et al. 1979).

As part of their multicentre study of premature infants, Lucas \& Cole (1990) examined characteristics of 51 suspected and 31 confirmed cases of NEC from a study population of more than 900 preterm infants. The risk of NEC was 10 times higher among formula fed infants than infants fed breast milk after adjustment for several potential confounders including length of gestation, birth weight, sex, respiratory disease, age at first enteral feed, and rate of incrementation of early feed volumes. The risk was 3.5 times higher in exclusively formula fed infants as compared with those fed both breast milk and formula. Among infants receiving breast milk, there was a sharp decline in the frequency of NEC with length of gestation. In contrast, there was no such decline among formula fed infants. In infants fed human milk, timing of the first feed was not related to frequency of NEC, but in formula fed infants delay in enteral feeding was associated with decreased risk of NEC.

Because there is no confirmed single cause of NEC, it is not known why breast feeding is protective. Several hypotheses have emerged. Specific nutrients that are abundant in human milk, such as glutamine and nucleotides, may be beneficial to gastrointestinal cell metabolism and function, improving the infant's ability to tolerate enteral feeds. Growth factors and hormones in human milk may directly improve gastrointestinal function and maturity (Kliegman et al. 1993). Immunological components of human milk may result in 
lower infection rates, which may play a role in the aetiology of NEC. Supplementation of preterm infants with immunoglobulins (IgA and $\operatorname{IgG}$ ) resulted in a decreased rate of NEC (Eibl et al. 1988). It has also been suggested that non-breast-milk feedings may result in "nutritionally induced inflammation" which may be caused by several mechanisms (Kliegman et al. 1993). Malabsorbed carbohydrates can serve as a substrate for microflora, which then ferment lactose to hydrogen gas and short chain fatty acids. The short chain fatty acids may then be toxic to the intestinal epithelial cells. Human milk lipids may be less toxic to the intestinal epithelium than those in formula. Undigested casein may also contribute to intestinal inflammation or injury (Kliegman et al. 1993). Human milk is known to have anti-inflammatory factors which may counter the inflammatory effect of feeding on the premature infant gut.

\section{RESPIRATORY DISEASES}

Results from epidemiological studies of the association between breast feeding and respiratory illness have been mixed. Most of these studies classified an infant as breast fed if that child received any breast milk regardless of the use of supplementary foods or fluids (Anderson et al. 1988; Wright et al. 1989; Woodward et al. 1990; Margo is et al. 1992; Douglas et al. 1994; Beaudry et al. 1995; Gessner et al. 1995; Wright et al. 1995). Among prospective studies meeting most of the criteria of Bauchner et al. (1986) breast feeding was protective against respiratory illness in many (Wright et al. 1989; Howie et al. 1990; Woodward et al. 1990; Holberg et al. 1991; Gessner et al. 1995; Wright et al. 1995) but not all (Anderson et al. 1988; Rubin et al. 1990; Margolis et al. 1992; Dewey et al. 1995) after controlling for other risk factors. Adequate information about breast feeding practices was available in only four of these studies.

Wright et al. (1989) conducted a study of respiratory disease among more than 1200 infants whose parents received medical care from a health maintenance organization in Arizona. Information on feeding practices was obtained at each medical visit. Any breast feeding was associated with a decreased incidence of wheezing illnesses but only in the first 4 months. In a follow-up study conducted when the children were 6 years of age, Wright et al. (1995) found that eleven \% of recurrent wheeze among non-atopic children could be attributed to not having been breast fed. In the study in Scotland described previously, Howie et al. (1990) found a reduction in respiratory illness from 0 to 13 and 40 to 52 weeks in infants who were breast fed for more than 13 weeks compared to those who were bottle fed. Rubin et al. (1990) did not find an association between infant feeding and respiratory illness. However, these investigators combined mixed fed groups for their published comparisons as previously described. Dewey et al. (1995) also did not observe any significant differences in the incidence or prevalence of respiratory illnesses between matched groups of breast fed and formula fed infants.

Case-control studies have been conducted comparing infant feeding characteristics among groups of infants with invasive lower respiratory illnesses. Two such studies (Istre et al. 1985; Cochi et al. 1986) showed that breast feeding was protective against invasive Haemophilus influenzae type $\mathrm{b}$ disease. In the first study, breast feeding was protective between 2 and 5 months but not between 6 and 11 months, controlling for day care, ethnicity, extreme crowding, and low family income (Cochi et al. 1986). In the second study (Istre et al. 1985), exclusive breast feeding was protective even after controlling for the number of siblings and day care attendance. Gessner et al. (1995) found that any breast feeding was protective against invasive disease caused by Streptococcus pneumoniae among Alaskan children in the first 2 years of life after controlling for day care attendance, parental tobacco use, and prior hospitalization for pneumonia. 


\section{OTITIS MEDIA}

More than half of all infants are affected by otitis media in the first year of life. Risk factors for otitis include ethnicity, male gender, orofacial abnormalities, use of day care, presence of siblings, maternal smoking, familial history of allergy and lack of breast feeding (Sheard, 1993). Several studies have shown a protective effect of breast feeding (Teele et al. 1989; Duncan et al. 1993; Owen et al. 1993; Dewey et al. 1995) while others have not (Tainio et al. 1988; Rubin et al. 1990; Niemela et al. 1995). Of these studies, six included adequate infant feeding information (Tainio et al. 1988; Howie et al. 1990; Rubin et al. 1990; Duncan et al. 1993; Owen et al. 1993; Dewey et al. 1995).

In a carefully designed study of more than 1000 infants enrolled in a health maintenance organization in Arizona, US, Duncan et al. (1993) prospectively examined the effect of breast feeding on the incidence of both acute and recurrent otitis media during the first year of life. Detailed information about the duration and exclusivity of breast feeding was obtained. Study infants who exclusively breast fed for 4 or more months had half as many episodes of acute otitis media as those not breast fed at all and $40 \%$ less than those who were partly breast fed. The recurrent otitis media rate in infants exclusively breast fed for 6 months or more was $10 \%$, compared with $20.5 \%$ in infants who were breast fed for less than 4 months. The effect of breast feeding on otitis media and recurrent otitis media remained significant after controlling for parental history of allergy, presence of one or more siblings, use of day care, maternal smoking, and gender.

In a prospective study of more than 500 infants in Texas, US, Owen et al. (1993) reported that any breast feeding was protective against otitis during the first 6 months, controlling for gender, ethnicity, birth order, socioeconomic status, feeding position, smoking and child care. Breast feeding was not reported to be protective against otitis at later ages but it is unclear how long infants were breast fed in this diverse population.

In another prospective study of 87 infants in California, US, the incidence of one or more episodes of otitis media during the first year of life was $19 \%$ lower in those who were breast fed throughout the first year of life than in formula fed infants (Dewey et al. 1995). Infants in this study were matched for characteristics such as birth weight, parental education and socioeconomic status, and data were analysed controlling for day care use. Parental smoking was rare in both groups. The percentage with prolonged episodes of otitis media (lasting more than $10 \mathrm{~d}$ ) during the first year was $80 \%$ lower among breast fed as compared with formula fed infants. Even in the second year of life, infants who had been breast fed were much less likely to have prolonged episodes of otitis media.

Infant feeding practices were not found to be associated with otitis media in the studies in Scotland and Denmark previously described (Howie et al. 1990; Rubin et al. 1990). In addition, exclusive breast feeding did not protect against recurrent otitis media in a study of 183 infants in Finland (Tainio et al. 1988). These infants were seen at medical clinic visits at 2, 4, 6, 9 and 12 months of age, and whenever they had any illnesses. During the second year, the children were only seen when ill. Only 28 children presented with recurrent otitis media (defined as five or more episodes of otitis during the first 2 years or four or more episodes in the second year). Characteristics of the 28 children were compared with those of 80 children who had no episodes of otitis media in the first 2 years of life. No significant differences were seen between groups in age of introduction of formula, cow's milk, or solid foods. However, the small sample size may have limited the ability to detect group differences. Furthermore, only $16 \%$ of infants in this population were breast fed less than 3.5 months. More than half the infants were breast fed for more than 6 months.

Several mechanisms may contribute to differences in incidence of otitis between feeding groups. Beauregard (1971) put forward the hypothesis that the position of the infant while 
feeding could result in differences in otitis. Because formula fed infants are more likely to be allowed to feed on their backs, milk may enter the middle ear via the Eustachian tube. However, this explanation may be too simplistic. Owen et al. (1993) reported that feeding position was related to the age of the infant during the first episode of otitis, but it was not related to subsequent ear infections. Laboratory evidence indicates that constituents in human milk may reduce otitis directly by affecting the ability of pathogens to attach or cause an inflammatory response (Backon, 1984; Hanson et al. 1985).

\section{BACTERAEMIA AND MENINGITIS}

Haemophilus influenzae infections have been shown to cause bacteraemia and meningitis in infants. Andersson et al. (1986) demonstrated that adhesion of these microorganisms to pharyngeal or buccal epithelial cells was inhibited by human milk. These findings have been corroborated by several feeding morbidity studies. Three studies in North America have shown that bottle fed infants have a 4- to 16-fold increased risk of $H$. influenzae bacteraemia and meningitis when compared with breast fed infants (Lun et al. 1982; Istre et al. 1985; Cochi et al. 1986). In Finland, children breast fed for longer than 6 months were less likely to have invasive $H$. influenzae infections during the second year of life (odds ratio $(\mathrm{OR})=0.47 ; \mathrm{CI}=0.3-0.9)$ than those who were not breast fed at least 6 months (Takala et al. 1989).

\section{INFANT BOTULISM}

Infant botulism is a rare but devastating illness caused by the release of toxin produced in the intestinal tract by Clostridium botulinum. The toxin binds irreversibly to the synaptic membrane of cholinergic nerves, preventing the release of acetylcholine. Untreated, infant botulism may cause respiratory arrest, brain damage and death (Wigginton \& Thill, 1993). Recovery occurs when the receptors on the affected nerves are replaced by new toxin free receptors. This process takes time and massive medical support. Although the mortality rate of infants hospitalized with infant botulism is less than $5 \%$, full recovery can take months (Wigginton \& Thill, 1993). Breast feeding was once considered a risk factor because most hospitalized cases were found to have been breast fed. However, when infants with botulism who died suddenly were compared with those who were hospitalized and recovered, formula fed infants were over-represented in the sudden death group, while most of the survivors were breast fed (Arnon et al. 1982). Formula fed infants tend to be younger at onset of infant botulism and experience more severe illness (Arnon et al. 1982).

While breast fed infants do become ill with botulism, they may be protected from the most devastating consequences of this disease. The intestinal flora differ between breast fed and formula fed infants, with the result that breast fed infants have more acidic faeces than formula fed infants. Multiplication of $C$. botulinum declines with $\mathrm{pH}$ and usually stops below pH 4.6 (Arnon, 1986). Additional foods or fluids alter the gut pH. In one study, the majority of patients with infant botulism had been given supplementary milks or foods within 4 weeks of onset (Long et al. 1985).

\section{URINARY TRACT INFECTION}

Neutral oligosaccharides, isolated from human milk, have been shown to inhibit bacterial binding to uroepithelial cells (Coppa et al. 1990). In response to this finding, Pisacane et al. (1992) conducted a case-control study comparing 128 hospitalized infants with urinary tract infection with 128 hospitalized control infants. All infants were less than 6 months of 
age. Three categories of feeding were defined based on type of feeding that the infant was receiving at the time of hospitalization: (1) exclusive breast feeding; (2) breast feeding combined with bottle feeding; (3) exclusive bottle feeding. The infants were matched for age, gender, social class, birth order and maternal smoking habits. Infants who were exclusively bottle fed at the time of admission to the hospital were more than five times as likely to have urinary tract infections compared to those who were breast fed.

In another study, the duration of exclusive breast feeding or partial breast feeding was significantly shorter among children from 2.5 months to 6 years old with pyelonephritis than among control children matched for age, sex and living area (Marild et al. 1990). A significant difference in duration of breast feeding during infancy was also present when only older children were included in the analyses, suggesting that there may be a lasting protective effect of breast feeding against urinary tract infection.

\section{CHRONIC ILLNESS}

Studies examining the impact of infant feeding on chronic diseases are limited by the length of time that often elapses between infancy and the onset of disease. Nearly all such studies are retrospective. Many rely on mothers' recall of infant feeding practices from many years before the onset of the illness. Information about duration and exclusivity of breast feeding may be particularly limited. Whenever possible, feeding practices are confirmed by paediatric medical records.

\section{INSULIN-DEPENDENT DIABETES MELLITUS}

Although the precise cause of type I insulin-dependent diabetes mellitus (IDDM) is not known, genetic, immunological and environmental factors appear to be involved (Mayer et al. 1988). In 1984, an inverse relationship between IDDM and breast feeding was reported in a Scandinavian population (Borch-Johnsen et al. 1984). This report was followed by several case-control studies comparing characteristics of children with IDDM with healthy siblings or matched controls. Case-control differences in infant feeding practices were reported by several researchers (Gerstein, 1994; Verge et al. 1994; Virtanen \& Aro, 1994) after controlling for confounding factors such as maternal age, education, and year of birth. Two studies that showed no relationship between infant feeding and IDDM were conducted in populations with an unusually low (Fort et al. 1986) or high (Samuelsson et al. 1993) prevalence of breast feeding as compared with the US. Breast feeding status at 2 weeks was not found to differ between cases and controls in a study conducted in Northern Ireland and Scotland (Patterson et al. 1994). Further information about the duration of breast feeding in these populations was not provided. Age at introduction of breast milk substitutes was significantly different between cases and controls among black but not white children in a US study (Kostraba et al. 1992). However, breast milk substitutes were introduced before 12 weeks in both groups.

Infectious agents have been thought to play a role in the aetiology of IDDM (Gamble, 1980; Handwerger et al. 1980; Champsaur et al. 1982; Yoon \& Ray, 1985). Immunologically active components of human milk may affect pathogenesis of IDDM directly by actively slowing or eliminating the proliferation of infectious agents (Mayer et al. 1988). More recently, another hypothesis regarding the link between infant feeding and IDDM has been proposed. Exposure to a protein found in cows' milk and formulas based on cows' milk has been implicated as a trigger for the autoimmune response that results in IDDM (Karjalainen et al. 1992). This report is supported by evidence in both humans (Savilahti et al. 1988; Saukkonen et al. 1994; Levy-Marchal et al. 1995) and animals (Elliott 
\& Martin, 1984; Daneman et al. 1987). However, the strength of the association between exposure to cows' milk proteins and IDDM has been questioned (Berdanier, 1995; Ellis \& Atkinson, 1996).

In an analysis combining the results from 19 studies of the relationship between infant feeding and IDDM, Gerstein (1994) concluded that early onset IDDM patients were more likely than healthy controls to have been breast fed for less than 3 months. In separate analyses, Gerstein also found that IDDM patients were more likely to have been exposed to cows' milk protein before 4 months of age. Risk for IDDM did not appear to increase when infants were given cows' milk after 4-6 months of age. Furthermore, infant feeding practices appeared to be related only to type I diabetes developing within the first few years of life. Gerstein estimated that up to $30 \%$ of type I diabetes cases could be prevented by removing cows' milk products from the diet of $90 \%$ of the population in the first 3 months.

In a case-control study involving nearly 700 IDDM children less than 15 years of age, Finnish researchers (Virtanen et al. 1993) found that the risk of IDDM was doubled in children who were exclusively breast fed for less than 2 months and doubled among those introduced to dairy products at less than 2 months of age. In multivariate analyses, introduction of cows' milk products was the most important risk factor and the relationship between breast feeding and IDDM was no longer significant when controlling for early introduction of cows' milk products.

In 1994, a work group was convened by the American Academy of Pediatrics to review studies which examined the association between infant feeding practices and IDDM (Drash et al. 1994). In their recommendations, the panel strongly endorsed breast feeding as the primary source of nutrition during the first year of life for all infants. In addition, they recommended that infants in families with a strong history of IDDM should not be fed products that contained intact cows' milk protein during the first year of life. The use of soya based infant formulas was also discouraged for either general or high risk infant feeding because of animal studies linking diabetes with soya protein intake. These recommendations have been the focus of considerable debate (Elliott, 1995; MacLean, 1995; Ellis \& Atkinson, 1996).

\section{CROHN'S DISEASE AND ULCERATIVE COLITIS}

Crohn's disease and ulcerative colitis are the two most common inflammatory bowel diseases (Calkins \& Mendeloff, 1986). Genetic factors and infectious agents have been implicated in the aetiology of Crohn's disease (Rigas et al. 1993). Lack of breast feeding was associated with risk of subsequent Crohn's disease in the early 1960s (Acheson \& Truelove, 1961). In 1979, Whorwell et al. (1979) reported that breast feeding was associated with a reduction in risk for ulcerative colitis but not Crohn's disease.

Rigas et al. (1993) compared the medical records of 68 patients with Crohn's disease and 39 patients with ulcerative colitis with those of 202 control subjects. All subjects were younger than 17 years of age. Breast feeding was negatively associated with Crohn's disease and marginally negatively associated with ulcerative colitis. Cases with Crohn's disease were about half as likely to have been breast fed as controls. However, missing data regarding maternal smoking habits make these results less convincing. Maternal smoking is positively associated with Crohn's disease (Persson et al. 1990) and negatively associated with breast feeding (Sauls, 1979).

Crohn's disease was also negatively associated with duration of any breast feeding in a study of 114 patients and 180 unaffected siblings (Koletzko et al. 1989). Cases were also more likely to have had diarrhoeal illnesses during infancy even when controlling for breast feeding status. Patients and controls did not differ in terms of sex, premature delivery, type 
of milk used for bottle feeding, age at introduction of solid foods, or length of exclusive breast feeding. In a later study from the same laboratory (Koletzko et al. 1991), no significant difference in relative risk for ulcerative colitis was found between breast fed and bottle fed children.

\section{CHILDHOOD CANCER}

Evidence that breast feeding may protect against childhood lymphoma has been limited to relatively small case-control studies. Davis et al. (1988) reported that children who were artificially fed or breast fed for less than 6 months were 6-9 times more likely than infants breast fed for at least 6 months to develop lymphoma before 15 years of age. This difference remained significant after controlling for infant sex, birth year, birth order, day care, family income, and maternal smoking during pregnancy, age, education and race. However, only 26 cases of lymphoma were available for analysis. In a larger study, childhood cancer was not associated with breast feeding (McKinney et al. 1987), but breast feeding exclusivity and duration were not considered. In Britain, a national cohort of more than 16000 infants was followed prospectively by the Child Health and Education Study (Golding et al. 1990). Comparisons were made between 33 children who developed cancer by the age of 10 and 99 matched controls. Only $28 \%$ of the children with cancer received any breast milk, compared with $46 \%$ of control children. While this finding was suggestive, the difference was not statistically significant. Similarly, a slight, though non-significant reduction in risk of lymphoma was observed among Chinese children who had received any breast milk during infancy compared with those who had not (Shu et al. 1995). Total duration of breast feeding and exclusive breast feeding were compared in 99 childhood cancer cases and 90 controls (Mathur et al. 1993). Cases and controls did not differ with respect to age, sex, birth year, birth order, maternal age or education, smoking of fathers and socioeconomic status. Duration of exclusive breast feeding was significantly longer among control subjects, primarily because of the differences between controls and cases with lymphoma. While it is possible that breast feeding is protective against childhood lymphoma, further evidence is needed to support this conclusion.

\section{ALLERGY}

The relationship between infant feeding practices and the onset and severity of atopic disease has been studied extensively and these studies have been reviewed by others (Kovar et al. 1984; Kramer, 1988; Bahna, 1991). It has been hypothesized that breast feeding is protective against allergic disease for two reasons. First, breast milk provides immunological factors that may protect the infant from absorption of intact allergens. Second, breast feeding results in delayed exposure to many allergenic compounds in foods. During the period of exclusive breast feeding, many infants are protected against symptoms of food allergy (Bahna, 1991). Whether this protection against allergy extends beyond the period of exclusive breast feeding has been the subject of considerable controversy. Epidemiological and clinical studies have produced inconsistent results (Kramer, 1988; Kay et al. 1994) and differences in the diagnostic criteria for atopic illness have limited the ability to make comparisons across studies. Many of these studies have been criticized for the same methodological flaws that plague other infant feeding studies. For example, exclusive breast feeding was rare or of short duration in the majority of cases. Mothers of infants with a high risk of atopy are often advised to breast feed their infants. Because of this, high risk infants may be over-represented among breast fed infants. Furthermore, very few studies have controlled for potential confounding factors (Kramer, 1988). 
In a recent follow-up study, a longer duration of breast feeding was found to be associated with reduced prevalence of atopic disease among children followed up between 1 and 3 years of age and again at age 17 years. Breast feeding for 6 months or longer was associated with reduction of atopic eczema for the first 3 years of life and with reduction in the most severe cases of atopy (those involving more than one organ or requiring medical intervention) at age 17 years (Saarinen \& Kajosaari, 1995). Breast feeding for longer than 1 month was associated with reduced symptoms of food allergy at 3 years and respiratory allergy at 17 years. However, potential confounding factors such as maternal smoking were not considered.

In his review, Kramer points out that the inconsistent results are not explained by differences in degree or duration of breast feeding; however, few of the earlier studies attempted to control maternal diet (Kramer, 1988). Several studies suggest that maternal diet during lactation, and perhaps during pregnancy, may affect atopic symptoms in the breast fed infant (Warner, 1980; Cant et al. 1985; Sigurs et al. 1992; Bardare et al. 1993). Case reports indicate that components of foods and fluids that mothers consume may be passed to infants via breast milk (Cant et al. 1985; Harmatz et al. 1987). However, not all researchers have found a relationship between maternal diet and infant atopy (Zeiger $e t$ al. 1986; Lilja et al. 1991). Typically, the elimination diets used in these studies have focused on the removal of proteins considered to be allergenic but other components of the mothers' diets must also be considered. Atopic eczema in infants has been associated with abnormal serum lipids (Manku et al. 1982; Rocklin et al. 1986; Bordoni et al. 1988; Wright \& Bolton, 1989). Allergic infants may be limited in their ability to convert dietary fatty acids to long chain polyunsaturated metabolites (Wright, 1985). Concentrations of fatty acids in human milk are susceptible to changes in maternal diet (Jensen, 1989). Carefully designed studies are necessary to understand the complex relationship between maternal diet and atopic disease in the breast fed infant.

\section{BREAST FEEDING AND INFANT MORTALITY}

\section{INFANT MORTALITY FROM ALL CAUSES}

In developing countries, breast feeding is clearly linked to child survival. Relative risk of mortality is consistently higher among artificially fed infants, particularly from diarrhoeal diseases (Huffman \& Combest, 1990; Cunningham et al. 1991; Institute of Medicine, 1991; Mitra \& Rabbani, 1995). In the US and other industrialized nations, little recent information is available regarding the impact of breast feeding on infant mortality. Between 1850 and 1950, more than a dozen studies examined the relationship between infant feeding and infant mortality in industrialized countries (Institute of Medicine, 1991). The results of these studies were summarized by Wray (1990). Although mortality rates dropped dramatically during that century, the relative advantage of breast fed infants persisted throughout. Since the 1950 s, mortality rates among both breast and bottle fed infants have continued to drop in developed countries and there is no published information on whether breast feeding still confers advantages for survival in the general population.

\section{SUDDEN INFANT DEATH SYNDROME}

Sudden infant death syndrome (SIDS), first formally defined in 1969, is the sudden and unexpected death of an apparently healthy infant whose death remains unexplained after autopsy, examination of the death scene, and review of the case history (Valdes-Dapena, 1991). Thus, SIDS is a diagnosis of exclusion, used when other potential causes of death 
are ruled out. Although unexplained death among infants has been documented for centuries, there are no positive diagnostic criteria and none of the various theories regarding its aetiology has been universally accepted (Valdes-Dapena, 1991).

Much of the research on SIDS has been focused on identification of risk factors. The most consistent of these factors is infant age. More than $90 \%$ of SIDS infants die during the post neonatal period (from 28 to 364 days) and, for unknown reasons, SIDS deaths peak at 8-9 weeks and again at 13-15 weeks (Anon. 1993). Other factors linked to an increased risk of SIDS are: family history of SIDS, low birth weight, maternal age, maternal cigarette smoking during and after pregnancy, other passive smoke exposure, parity, ethnicity (the rate among Afro-American infants is twice that of white infants), lower socioeconomic conditions and infant sleep position (Anon. 1993).

Lack of breast feeding has been a significant risk factor for SIDS in several studies (Watson et al. 1981; Murphy et al. 1982; Carpenter et al. 1983; Hoffman et al. 1988; Ford et al. 1993), even after controlling for several social and demographic factors. However, infant feeding was not associated with SIDS in the US Collaborative Perinatal Project after controlling for maternal education and birth weight (Kraus et al. 1989). In that study, breast feeding exclusivity and duration were not considered. In the New Zealand Cot Death Study (Ford et al. 1993) exclusive breast feeding was protective against SIDS after controlling for infant age, region, season, maternal age, smoking habits and education, infant sex, birth weight, prematurity, ethnicity, and sleep position. In a recent study, breast feeding was found to be protective against SIDS among infants of non-smoking mothers but not infants of smoking mothers after adjusting for birth weight, sleeping position, prenatal care, medical conditions at birth and maternal smoking during pregnancy (Klonoff-Cohen et al. 1995).

The potential mechanisms for an association between infant feeding and SIDS have not been thoroughly investigated. Because SIDS has been associated with infectious agents including infant botulism (Arnon, 1983; Blackwell et al. 1992; Fleming, 1992; An et al. 1993; Blackwell et al. 1993; Saadi et al. 1993), it is possible that the protective effect of breast feeding is related to the immunological components of breast milk. Alternatively, breast feeding may reduce infant risk for SIDS because breast fed infants have shorter periods of uninterrupted sleep and lower exposure to agents that cause anaphylactic reaction (Bernshaw, 1991).

\section{CONCLUSIONS}

The last decade has produced an enormous amount of new information regarding the health effects of breast feeding. The bulk of this research confirms that breast feeding provides both long and short term benefits to infants. The following statements summarize the evidence to date:

- Human milk contains a variety of hormones and hormone-like substances which contribute to the physiological development of the infant.

- In many studies, there are small but consistent differences in scores on cognitive tests between breast fed and artificially fed infants. Human milk contains long chain fatty acids which may promote maturation of the brain and nervous system.

- Many of the immunological components of breast milk are well characterized. Breast feeding is protective against several diseases, not only in developing but also in industrialized countries. Evidence is strong that breast feeding protects against diarrhoeal and lower respiratory disease as well as otitis media. Breast feeding may also be protective against necrotizing enterocolitis, bacteraemia, meningitis, botulism and 
urinary tract infection. Breast feeding has also been reported in some studies to be protective against diabetes, inflammatory bowel disease and childhood lymphoma.

- Lack of breast feeding may be a significant risk factor for sudden infant death. Both immunological and behavioural aspects of breast feeding may reduce the risk of SIDS.

Despite the recent advances in our understanding of the health advantages of breast feeding, further research is needed in some areas. Studies designed with rigorous attention to methodological criteria are necessary to examine further the role that breast feeding may play in the prevention of diabetes, childhood cancer, atopic disease, and sudden infant death. Further work is also needed to determine how infant feeding practices may affect cognitive and motor development during infancy and childhood. Experimental trials in which certain constituents of human milk are added to infant formulas would help to elucidate the mechanisms for the health effects of breast feeding. However, it is unlikely that such formulas will be able to mimic completely the physiological properties of human milk (Goedhart \& Bindels, 1994). Finally, given that many studies have focused primarily on homogeneous populations of infants from upper income, highly educated families, it is important to examine the effect of infant feeding practices in more diverse populations. This should be more feasible as increasing numbers of women in industrialized countries breast feed their infants.

\section{REFERENCES}

Acheson, E. D. \& Truelove, S. C. (1961). Early weaning in the aetiology of ulcerative colitis: a study of feeding in infancy in cases and controls, British Medical Journal ii, 929-933.

Ahmed, F., Clemens, J. D., Rao, M. R., Sack, D. A., Khan, M. R. \& Haque, E. (1992). Community-based evaluation of the effect of breastfeeding on the risk of microbiologically confirmed or clinically presumptive shigellosis in Bangladeshi children. Pediatrics $90,406-411$.

An, S. F., Gould, S., Keeling, J. W. \& Fleming, K. A. (1993). Role of respiratory viral infection in SIDS: detection of viral nucleic acid by in situ hybridization. Journal of Pathology 171, 271-278.

Anderson, L. J., Parker, R. A., Strikas, R. A., Farrar, J. A., Gangarosa, E. J., Keyserling, H. L. \& Sikes, R. K. (1988). Day-care centre attendance and hospitalization for lower respiratory tract illness. Pediatrics 82, 300-308.

Andersson, B., Porras, O., Hanson, L. Å., Lagergård, T. \& Svanborg-Eden, C. (1986). Inhibition of attachment of Streptococcus pneumoniae and Haemophilus influenzae by human milk and receptor oligosaccharides. Journal of Infectious Diseases 153, 232-237.

Anon. (1993). Variations in the incidence of sudden infant death syndrome (SIDS), United States, $1980-1988$. Statistical Bulletin 10-18.

Arnon. S. S. (1983). Breast-feeding and toxigenic intestinal infections: missing links in SIDS? In Sudden Infant Death Syndrome, pp. 539-555 [J. T. Tildon, L. M. Roeder and A. Steinschneider, editors]. New York: Academic Press.

Arnon, S. S. (1986). Infant botulism: anticipating the second decade. Journal of Infectious Diseases 154, $201-206$.

Arnon, S. S., Damus, K., Thompson, B., Midura, T. F. \& Chin, J. (1982). Protective role of human milk against sudden death from infant botulism. Journal of Pediatrics 100, 568-573.

Backon, J. (1984). Prolonged breastfeeding as a prophylaxis for recurrent otitis media: relevance of prostaglandins. Medical Hypotheses 13, 161.

Bahna, S. L. (1991). Breast milk and special formulas in prevention of milk allergy. In Immunol Milk Neo, pp. 445-451 [J. Mestecky, editor]. New York: Plenum Press.

Bardare, M., Vaccari, A., Allievi, E., Brunelli, L., Coco, F., de Gaspari, G. C. \& Flauto, U. (1993). Influence of dietary manipulation on incidence of atopic disease in infants at risk. Annals of Allergy 71, 366-371.

Bauchner, H., Leventhal, J. M. \& Shapiro, E. D. (1986). Studies of breast-feeding and infections. How good is the evidence? Journal of the American Medical Association 256, 887-892.

Beaudry, M., Dufour, R. \& Marcoux, S. (1995). Relation between infant feeding and infections during the first six months of life. Journal of Pediatrics 126, 191-197.

Beauregard, W. G. (1971). Positional otitis media. Journal of Pediatrics 79, 294-296.

Berdanier, C. D. (1995). Diet, autoimmunity, and insulin-dependent diabetes mellitus: a controversy. Proceedings of the Society for Experimental Biology and Medicine 209, 223-230.

Bernshaw, N. J. (1991). Does breastfeeding protect against sudden infant death syndrome? Journal of Human Lactation 7, 73-79. 
Birch, E. E., Birch, D. G., Hoffman, D. R., Hale, L., Everett, M. \& Uauy, R. (1993). Breast-feeding and optimal visual development. Journal of Pediatric Ophthalmology and Strabismus 30, 33-38.

Bjerve, K. S., Brubakk, A. M., Fougner, K. J., Johnsen, H., Midthjell, K. \& Vik, T. (1993). Omega-3 fatty acids: essential fatty acids with important biological effects, and serum phospholipid fatty acids as markers of dietary (o-3 fatty acid intake. American Journal of Clinical Nutrition 57 (Suppl.) 801S-805S.

Blackburn, S. L. \& Loper, D. L. (1992). The gastrointestinal and hepatic systems and perinatal nutrition. In Maternal, Fetal and Neonatal Physiology, pp. 379-431. Philadelphia, PA: W. B. Saunders.

Blackwell, C. C., Saadi, A. T., Raza, M. W., Stewart, J. \& Weir, D. M. (1992). Susceptibility to infection in relation to SIDS. Journal of Clinical Pathology 45 (Suppl.) 20-24.

Blackwell, C. C., Saadi, A. T., Raza, M. W., Weir, D. M. \& Busuttil, A. (1993). The potential role of bacterial toxins in sudden infant death syndrome (SIDS). International Journal of Legal Medicine 105, 333-338.

Borch-Johnsen, K., Joner, G., Mandrup-Poulsen, T., Christy, M., Zachau-Christiansen, B., Kastrup, K. \& Nerup, J. (1984). Relation between breastfeeding and incidence rates of insulin-dependent diabetes mellitus. Lancet ii, $1083-1086$.

Bordoni, A., Biagi, P. L., Masi, M., Ricci, G., Fanelli, C., Patrizi, A. \& Ceccolini, E. (1988). Evening primrose oil (Efamol) in the treatment of children with atopic eczema. Drugs under Experimental and Clinical Research 14. 291-297.

Brown, K. H., Stallings, R. Y., Creed de Kanashiro, H., Lopez de Romana, G. \& Black, R. E. (1990). Effects of common illnesses on infants' energy intakes from breast milk and other foods during longitudinal communitybased studies in Huascar (Lima), Peru. American Journal of Clinical Nutrition 52, $1005-1013$.

Buescher, E. S. (1994). Host defense mechanisms of human milk and their relations to enteric infections and necrotizing enterocolitis. Clinical Perinatology 21, 247-262.

Butte, N. F., Wong, W. W., Ferlic, L., O’Brian Smith, E., Klein, P. D. \& Garza, C. (1990). Energy expenditure and deposition of breastfed and formula-fed infants during early infancy. Pediatric Research 28, 631-640.

Calkins, B. M. \& Mendeloff, A. 1. (1986). Epidemiology of inflammatory bowel disease. Epidemiologic Reviews 8 , $60-91$.

Cant, A., Marsden, R. A. \& Kilshaw, P. J. (1985). Egg and cows' milk hypersensitivity in exclusively breastfed infants with eczema, and detection of egg protein in breast milk. British Medical Journal 291, $932-935$.

Carlson, S. E. (1989). Polyunsaturated fatty acids and infant nutrition. In Dietary omega-3 and omega-6 Fatty Acids: Biological Effects and Nutritional Essentiality, pp. 147-158 [G. C. Simopoulos and A. P. Simopoulos, editors]. New York: Plenum Press.

Carlson, S. E., Werkman, S. H., Rhodes, P. G. \& Tolley, E. A. (1993). Visual-acuity development in healthy preterm infants: effect of marine-oil supplementation. American Journal of Clinical Nutrition 58, 35-42.

Carpenter, R. G., Gardner, A., Jepson, M., Taylor, E. M., Salvin, A., Sunderland, R., Emery, J. L., Pursall, E. \& Roe, J. (1983). Prevention of unexpected infant death: evaluation of the first seven years of the Sheffield Intervention Programme. Lancet i, 723-727.

Cavell, B. (1981). Gastric emptying in infants fed human milk or infant formula. Acta Paediatrica Scandinavica 70, 639-641.

Champsaur, H. F., Bottazzo, G. F., Bertrams, J., Assan, R. \& Bach, C. (1982). Virologic, immunologic, and genetic factors in insulin-dependent diabetes mellitus. Journal of Pediatrics 100, 15-20.

Clemens, J., Rao, M., Ahmed, F., Ward, R., Huda, S., Chakraborty, J., Yunus, M., Khan, M. R., Ali, M., Kay, B., van Loon, F. \& Sack, D. (1993). Breastfeeding and the risk of life-threatening rotavirus diarrhea: prevention or postponement? Pediatrics 92, 680-685.

Clemens, J. D., Stanton, B., Stoll, B., Shahid, N. S., Banu, H. \& Chowdhury, A. K. M. A. (1986). Breastfeeding as a determinant of severity in shigellosis. Evidence for protection throughout the first three years of life in Bangladeshi children. American Journal of Epidemiology 123, 710-720.

Cochi, S. L., Fleming, D. W., Hightower, A. W., Limpakarnjanarat, K., Facklam, R. R., Smith, J. D., Sikes, R. K. \& Broome, C. V. (1986). Primary invasive Haemophilus influenzae type b disease: a population-based assessment of risk factors. Journal of Pediatrics 108, 887-896.

Colombo, J. (1993). Infant Cognition: Predicting Later Intellectual Functioning. Newbury Park, CA: Sage Publications.

Coppa, G. V., Gabrielli, O., Giorgi, P., Catassi, C., Montanari, M. P., Varaldo, P. E. \& Nichols, B. L. (1990). Preliminary study of breastfeeding and bacterial adhesion to uroepithelial cells. Lancet 335, 569-571.

Crawford, M. A. (1993). The role of essential fatty acids in neural development: implications for perinatal nutrition. American Journal of Clinical Nutrition 57 (Suppl.) 703S-709S.

Cunningham, A. S., Jelliffe, D. B. \& Jelliffe, E. F. P. (1991). Breastfeeding and health in the 1980s: a global epidemiologic review. Journal of Pediatrics 118, 659-666.

Daneman, D., Fishman, L., Clarson, C. \& Martin, J. M. (1987). Dietary triggers of insulin-dependent diabetes in the BB rat. Diabetes Research 5, 93-97.

Davis, M. K., Savitz, D. A. \& Graubard, B. I. (1988). Infant feeding and childhood cancer. Lancet ii, 365-368. de Zoysa, I., Rea, M. \& Martines, J. (1991). Why promote breastfeeding in diarrheal disease control programmes? Health Policy and Planning 6, 371-379.

Dewey, K. G., Heinig, M. J. \& Nommsen-Rivers, L. A. (1995). Differences in morbidity between breast-fed and formula-fed infants. Journal of Pediatrics 126, 696-702. 
Douglas, R. M., Woodward, A., Miles, H., Buetow, S. \& Morris, D. (1994). A prospective study of proneness to acute respiratory illness in the first two years of life. International Journal of Epidemiology 23, 818-826.

Drash, A. L., Kramer, M. S., Swanson, J. \& Udall, J. N. (1994). Infant feeding practices and their possible relationship to the etiology of diabetes mellitus. Pediatrics 94, 752-754.

Duffy, L. C., Byers, T. E., Riepenhoff-Talty, M., La Scolea, L. J., Zielezny, M. \& Ogra, P. L. (1986). The effects of infant feeding on rotavirus-induced gastroenteritis: a prospective study. American Journal of Public Health 76, 259-263.

Duncan, B., Ey, J., Holberg, C. J., Wright, A. L., Martinez, F. D. \& Taussig, L. M. (1993). Exchusive breastfeeding for at least 4 months protects against otitis media. Pediatrics 91, 867-872.

Eibl, M. M., Wolf, H. M., Fürnkranz, H. \& Rosenkranz, A. (1988). Prevention of necrotizing enterocolitis in lowbirth-weight infants by IgA-IgG feeding. New England Journal of Medicine 319, 1-7.

Elliott, R. B. (1995). Cow's milk and the diabetes debate. Pediatrics 96, 541 .

Elliott, R. B. \& Martin, J. M. (1984). Dietary protein: a trigger of insulin-dependent diabetes in the BB rat? Diabetologia 26, 297-299.

Ellis, T. M. \& Atkinson, M. A. (1996). Early infant diets and insulin-dependent diabetes. Lancet 347, 1464-1465.

Feachem, R. G. \& Koblinsky, M. A. (1984). Interventions for the control of diarrheal diseases in young children: promotion of breastfeeding. Bulletin of the World Health Organization 62, 271.

Fergusson, D. M., Beautrais, A. L. \& Silva, P. A. (1982). Breastfeeding and cognitive development in the first seven years of life. Social Science and Medicine 16, 1705-1708.

Fleming, K. A. (1992). Viral respiratory infection and SIDS. Journal of Clinical Pathology 45 (11, Suppl.), $29-32$.

Ford, R. P. K., Taylor, B. J., Mitchell, E. A., Enright, S. A., Stewart, A. W., Becroft, D. M., Scragg, R., Hassall, I. B., Barry, D. M. J., Allen, E. M. \& Roberts, A. P. (1993). Breastfeeding and the risk of sudden infant death syndrome. International Journal of Epidemiology 22, 885-890.

Fort, P., Lanes, R., Dahlem, S., Recker, B., Weyman-Daum, M., Pugliese, M. \& Lifshitz, F. (1986). Breastfeeding and insulin-dependent diabetes mellitus in children. Journal of the American College of Nutrition 5, 439-441.

Gamble, D. R. (1980). The epidemiology of insulin dependent diabetes, with particular reference to the relationship of virus infection to its etiology. Epidemiologic Reviews 2, 49-70.

Gerstein, H. C. (1994). Cow's milk exposure and type I diabetes mellitus. Diabetes Care 17, 13-19.

Gessner, B. D., Ussery, X. T., Parkinson, A. J. \& Breiman, R. F. (1995). Risk factors for invasive disease caused by Streptococcus pneumoniae among Alaska native children younger than two years of age. Pediatric Infectious Disease Journal 14, 123-128.

Goedhart, A. C. \& Bindels, J. G. (1994). The composition of human milk as a model for the design of infant formulas: recent findings and possible applications. Nutrition Research Reviews 7, 1-23

Golding, J., Paterson, M. \& Kinlen, L. J. (1990). Factors associated with childhood cancer in a national cohort study. British Journal of Cancer 62, 304-308.

Goldman, A. S., Chheda, S., Keeney, S. E., Schmalstieg, F. C. \& Schanler, R. J. (1994). Immunologic protection of the premature newborn by human milk. Seminars in Perinatology 18, 495-501.

Grosvenor, C. E., Picciano, M. F. \& Baumrucker, C. R. (1993). Hormones and growth factors in milk. Endocrine Reviews 14, 710-728.

Handwerger, B. S., Fernandes, G. \& Brown, D. M. (1980). Immune and autoimmune aspects of diabetes mellitus. Human Pathology 11, 338-352.

Hanson, L. A, Ahlstedt, S., Andersson, B., Carlsson, B., Fallstrom, S. P., Mellander, L., Porras, O., Soderstrom, T. \& Svanborg Eden, C. (1985). Protective factors in milk and the development of the immune system. Pediatrics 75 (Suppl.) 172-176.

Harmatz, P. R., Hanson, D. G., Brown, M., Kleinman, R. E., Walker, W. A. \& Bloch, K. J. (1987). Transfer of maternal food proteins in milk. In Human Lactation. 3. The Effects of Human Milk on the Recipient Infant, pp. 289-299 [A. S. Goldman, S. A. Atkinson and L. A. Hanson, editors]. New York: Plenum Press.

Hoffman, H. J., Damus, K., Hillman, L. \& Krongrad, E. (1988). Risk factors for SIDS. Results of the National Institute of Child Health and Human Development SIDS Cooperative Epidemiological Study. Annals of the New York Academy of Sciences 533, 13-31

Holberg, C. J., Wright, A. L. \& Martinez, F. D. (1991). Risk factors for respiratory syncytial virus-associated lower respiratory illness in the first year of life. Journal of Epidemiology 133, 1135-1151.

Howie, P. W., Forsyth, J. S., Ogston, S. A., Clark, A. \& Florey, C. du V. (1990). Protective effect of breast feeding against infection. British Medical Journal 300, 11-16.

Huffman, S. L. \& Combest, C. (1990). Role of breastfeeding in the prevention and treatment of diarrhea. Journal of Diarrheal Diseases Research 8, 68-81.

Ichiba, H., Kusuda, S., Itagane, Y., Fujita, K. \& Issiki, G. (1992). Measurement of growth promoting activity in human milk using a fetal small intestinal cell line. Biology of the Neonate 61, 47-53

Institute of Medicine (1991). Nutrition during Lactation. Washington, DC: National Academy Press.

Istre, G. R., Conner, J. S., Broome, C. V., Hightower, A. \& Hopkins, R. S. (1985). Risk factors for primary invasive Haemophilus influenzae disease: increased risk from day care attendance and school-aged household members. Journal of Pediatrics 106, 190-195.

Jensen, R. G. (1989). The Lipids of Human Milk. Boca Raton, FL: CRC Press.

Karjalainen, J., Martin, J. M., Knip, M., Ilonen, J., Robinson, B. H., Savilahti, E., Akerblom, H. K. \& Dosch, 
H. M. (1992). A bovine albumin peptide as a possible trigger of insulin-dependent diabetes mellitus. New England Journal of Medicine 327, 302-307.

Kay, J., Gawkrodger, D. J., Mortimer, M. J. \& Jaron, A. G. (1994). The prevalence of childhood atopic eczema in a general population. Journal of the American Academy of Dermatology 30, 35-39.

Kliegman, R. M. (1979). Neonatal necrotizing enterocolitis: implications for an infectious disease. Pediatric Clinic's of North America 26, 327-344.

Kliegman, R. M. \& Fanaroff, A. A. (1984). Necrotizing enterocolitis. New England Journal of Medicine 310, $1093-1103$.

Kliegman, R. M., Walker, W. A. \& Yolken, R. H. (1993). Necrotizing enterocolitis: research agenda for a disease of unknown etiology and pathogenesis. Pediatric Research 34, 701-708.

Klonoff-Cohen, H. S., Edelstein, S. L., Lefkowitz, E. S., Srinivasan, I. P., Kaegi, D., Chang, J. C. \& Wiley, K. J. (1995). The effect of passive smoking and tobacco exposure through breast milk on sudden infant death syndrome [see comments]. Journal of the American Medical Association 273, 795-798.

Koldovsky, O. (1994). Maturative effects of hormones on the developing mammalian gastrointestinal tract. Acta Paediatrica (Suppl. 405) 7-12.

Koletzko, S., Griffiths, A., Corey, M., Smith, C. \& Sherman; P. (1991). Infant feeding practices and ulcerative colitis in childhood. British Medical Journal 302, 1580-1581.

Koletzko, S., Sherman, P., Corey, M., Griffiths, A. \& Smith, C. (1989). Role of infant feeding practices in development of Crohn's disease in childhood. British Medical Journal 298, 1617-1618.

Kostraba, J. N., Dorman, J. S., LaPorte, R. E., Scott, F. W., Steenkiste, A. R., Gloninger, M. \& Drash, A. L. (1992). Early infant diet and risk of IDDM in blacks and whites. A matched case-control study. Diabetes Care $15,626-631$.

Kovar, M. G., Serdula, M. K., Marks, J. S. \& Fraser, D. W. (1984). Review of the epidemiologic evidence for an association between infant feeding and health. Pediatrics 74 (Suppl.) 615638

Kramer, M. (1987). Breastfeeding and child health. Methodologic issues in epidemiologic research. In Human Lactation. 3. The Effects of Human Milk on the Recipient Infant, pp. 339-360 [A. S. Goldman, S. A. Atkinson and L. A. Hanson, editors]. New York: Plenum Press.

Kramer, M. S. (1988). Does breastfeeding help protect against atopic disease? Biology, methodology, and a golden jubilee of controversy. Journal of Pediatrics 112, 181-190.

Kraus, J. F., Greenland, S. \& Bulterys, M. (1989). Risk factors for sudden infant death syndrome in the US Collaborative Perinatal Project. International Journal of Epidemiology 18, 113-120.

Kunz, C. \& Rudloff, S. (1993). Biological functions of oligosaccharides in human milk. Acta Paediatrica 82, 903-912.

Labbok, M. \& Krasovec, K. (1990). Toward consistency in breastfeeding definitions. Studies in Family Planning 21, 226-230.

Lanting, C. I., Fidler, V., Huisman, M., Touwen, B. C. L. \& Boersma, E. R. (1994). Neurological differences between 9-year-old children fed breast milk or formula-milk as babies. Lancet 344, 1319-1322.

Lawrence, P. B. (1994a). Breast milk: best source of nutrition for term and preterm infants. Pediatric Clinics of North America 41, 925-941.

Lawrence, R. A. (1994b). Breastfeeding: a Guide for the Medical Profession. St Louis, MO: Mosby.

Levy-Marchal, C., Karjalainen, J., Dubois, F., Karges, W., Czernichow, P. \& Dosch, H. M. (1995). Antibodies against bovine albumin and other diabetes markers in French children. Diabetes Care 18, 1089-1094.

Lilja, G., Dannaeus, A., Foucard, T., Graff-Lonnevig, V., Johansson, S. G. O. \& Oman, H. (1991). Effects of maternal diet during late pregnancy and lactation on the development of IgE and egg- and milk-specific IgE and $\operatorname{lgG}$ antibodies in infants. Clinical and Experimental Allergy 21, 195-202.

Long. S. S., Gajewski, J. L., Brown, L. W. \& Gilligan, P. H. (1985). Clinical, laboratory, and environmental features of infant botulism in southeastern Pennsyivania. Pediatrics 75, 935-941.

Lucas, A. \& Cole, T. J. (1990). Breast milk and neonatal necrotising enterocolitis. Lancet 336, 1519-1523.

Lucas, A., Gore, S. M., Cole, T. J., Bamford, M. F., Dossetor, J. F. B., Barr, I., Dicarlo, L., Cork, S. \& Lucas, P. J. (1984). Multicentre trial on feeding low birth weight infants: effects of diet on early growth. Archives of Disease in Childhood 59, 722-730.

Lucas. A., Lucas, P. J. \& Baum, J. D. (1981). Differences in the pattern of milk intake between breast and bottle fed infants. Early Human Development 5, 195-199.

Lucas, A., Morley, R. \& Cole, T. J. (1989). Early diet in preterm babies and developmental status in infancy. Archives of Disease in Childhood 64, 1570-1578.

Lucas, A., Morley, R., Cole, T. J. \& Gore, S. M. (1994). A randomised multicentre study of human milk versus formula and later development in preterm infants. Archives of Disease in Childhood 70 (Special Issue 2), F141-F146.

Lucas, A., Morley, R., Cole, T. J., Gore, S. M., Lucas, P. J., Crowle, P., Pearse, R., Boon, A. J. \& Powell, R. (1990). Early diet in preterm babies and developmental status at 18 months. Lancet 335, 1477-1481.

Lucas, A., Morley, R., Cole, T. J., Lister, G. \& Leeson-Payne, C. (1992). Breast milk and subsequent intelligence quotient in children born preterm. Lancet 339, 261-264.

Lun, M. K., Ward, J. L. \& Bender, T. R. (1982). Protective influence of breastfeeding on the risk of developing H. influenzae type b disease. Pediatric Research 16, 151A (Abstract 436).

McKinney, P. A., Cartwright, R. A., Saiu, J. M. T. et al. (1987). The inter-regional epidemiological study of 
childhood cancer (IRESCC): a case-control study of aetiological factors in leukaemia and lymphoma. Archives of Disease in Childhood 62, 279-287.

MacLean, W. C. (1995). Cow's milk and the diabetes debate. Pediatrics 96, 542.

Makrides, M., Neumann, M. A., Byard, R. W., Simmer, K. \& Gibson, R. A. (1994). Fatty acid composition of brain, retina, and erythrocytes in breast- and formula-fed infants. American Journal of Clinical Nutrition 60 , 189-194.

Makrides, M., Simmer, K., Goggin, M. \& Gibson, R. A. (1993). Erythrocyte docosahexaenoic acid correlates with the visual response of healthy, term infants. Pediatric Research 33, 425-427.

Manku, M.S., Horrobin, D. F., Morse, N., Kyte, V., Jenkins, K., Wright, S. \& Burton, J. L. (1982). Reduced levels of prostaglandin precursors in the blood of atopic patients: defective delta-6-desaturase function as a biochemical basis for atopy. Prostaglandins, Leukotrienes and Medicine 9, 615-628.

Margolis, P. A., Greenberg, R. A., Keyes, L. L., LaVange, L. M., Chapman, R. S., Denny, F. W., Bauman, K. E. \& Boat, B. W. (1992). Lower respiratory illness in infants and low socioeconomic status. American Journal of Public Health 82, $1119-1126$.

Marild, S., Jodal, U. \& Hanson, L. A. (1990). Breastfeeding and urinary-tract infection. Lancet $336,942$.

Mathur, G. P., Gupta, N., Mathur, S., Gupta, V., Pradham, S., Dwivedi, J. N., Tripathi, B. N., Kushwaha, K. P., Sathy, N. \& Modi, U. J. (1993). Breastfeeding and childhood cancer. Indian Pediatrics 30, 651-657.

Mayer, E. J., Hamman, R. F., Gay, E. C., Lezotte, D. C., Savitz, D. A. \& Klingensmith, G. J. (1988). Reduced risk of IDDM among breastfed children: the Colorado IDDM registry. Diabetes 37, 1625-1632.

Mitra, A. K. \& Rabbani, F. (1995). The importance of breastfeeding in minimizing mortality and morbidity from diarrhoeal diseases: the Bangladesh perspective. Journal of Diarrhoeal Diseases Research 13, 1-7.

Moriarty, R. R., Finer, N. N., Cox, S. F., Phillips, H. J., Theman, A., Stewart, A. R. \& Ulan, O. A. (1979). Necrotizing enterocolitis and human milk. Journal of Pediatrics 94, 295-296.

Morley, R., Cole, T. J., Powell, R.\& Lucas, A. (1988). Mother's choice to provide breast milk and developmental outcome. Archives of Disease in Childhood 63, 1382-1385.

Morrow, A. L., Reves, R. R., West, M. S., Guerrero, M. L., Ruiz-Palacios, G. M. \& Pickering, L. K. (1992). Protection against infection with Giardia lamblia by breastfeeding in a cohort of Mexican infants. Journal of Pediatrics 121, 363-370.

Morrow-Tlucak, M., Haude, R. H. \& Ernhart, C. B. (1988). Breastfeeding and cognitive development in the first 2 years of life. Social Science and Medicine 26, 635-639.

Murphy, J. F., Newcombe, R. J. \& Sibert, J. R. (1982). The epidemiology of sudden infant death syndrome. Journal of Epidemiology and Community Health 36, 17-21.

Nachamkin, I., Fischer, S. H., Yang, X., Benitez, O. \& Cravioto, A. (1994). Immunoglobulin A antibodies directed against Campylobacter jejuni flagellin present in breast milk. Epidemiology of Infection 112, $359-365$.

Nettleton, J. A. (1993). Are n-3 fatty acids essential nutrients for fetal and infant development? Journal of the American Dietetic Association 93, 58-64.

Niemela, M., Uhari, M. \& Mottonen, M. (1995). A pacifier increases the risk of recurrent acute otitis media in children in day care centers. Pediatrics 96, 884888.

Orlando, S. (1995). The immunologic significance of breast milk. Journal of Obstetric, Gynecologic and Neonatal Nursing 24, 678-683.

Owen, M. J., Baldwin, C. D., Swank, P. R., Pannu, A. K., Johnson, D. L. \& Howie, V. M. (1993). Relation of infant feeding practices, cigarette smoke exposure, and group child care to the onset and duration of otitis media with effusion in the first two years of life. Journal of Pediatrics 123, 702-711.

Patterson, C. C., Waugh, N. R., Carson, D. J., Cole, S. K. \& Hadden, D. R. (1994). A case-control investigation of perinatal risk factors for childhood IDDM in Northern Ireland and Scotland. Diabetes Care 17, 376-381.

Persson, P. G., Ahlbom, A. \& Hellers, G. (1990). Inflammatory bowel disease and tobacco smoke - a case-control study. Gut 31, 1377--1381.

Pisacane, A., Graziano, L., Mazzarella, G., Scarpellino, B. \& Zona, G. (1992). Breastfeeding and urinary tract infection. Journal of Pediatrics 120, 87-89.

Polk, D. H. (1992). Do breast milk derived hormones play a role in neonatal development? Early Human Development 29, 329-331.

Ponder, D. L., Innis, S. M., Benson, J. D. \& Siegman, J. S. (1992). Docosahexaenoic acid status of term infants fed breast milk or infant formula containing soy oil or corn oil. Pediatric Research 32, 683-688.

Popkin, B. M., Adair, L., Akin, J. S., Black, R., Briscoe, J. \& Flieger, W. (1990). Breastfeeding and diarrheal morbidity. Pediatrics 86, 874-882.

Rigas, A., Rigas, B., Glassman, M., Yen, Y., Lan, S. J., Petridou, E., Hsieh, C. \& Trichopoulos, D. (1993). Breastfeeding and maternal smoking in the etiology of Crohn's disease and ulcerative colitis in childhood. Annals of Epidemiology 3, 387-392.

Rocklin, R. E., Thistle, L., Gallant, L., Manku, M. S. \& Horrobin, D. (1986). Altered arachidonic acid content in polymorphonuclear and mononuclear cells from patients with allergic rhinitis and/or asthma. Lipids 21, $17-20$.

Rodgers, B. (1978). Feeding in infancy and later ability and attainment: a longitudinal study. Developmental Medicine and Child Neurology 20, 421-426. 
Rogan, W. J. \& Gladen, B. C. (1993). Breastfeeding and cognitive development. Early Human Development 31. $181-193$.

Rubin, D. H., Leventhal, J. M., Krasilnikoff, P. A., Kuo, H. S., Jekel, J. F., Weile, B., Levee, A., Kurzon, M. \& Berget, A. (1990). Relationship between infant feeding and infectious illness: a prospective study of infants during the first year of life. Pediatrics $85,464-471$.

Ruff, A. J. (1994). Breastmilk, breastfeeding, and transmission of viruses to the neonate. Seminars in Perinatology 18. $510-516$.

Ruuska, T. (1992). Occurrence of acute diarrhoea in atopic and nonatopic infants: the role of prolonged breastfeeding. Journal of Pediatric Gastroenterology and Nutrition 14, 27-33.

Saadi, A. T., Blackwell, C. C., Raza, M. W., James, V. S., Stewart, J., Elton, R. A. \& Weir, D. M. (1993). Factors enhancing adherence of toxigenic Staphylococcus aureus to epithelial cells and their possible role in sudden infant death syndrome. Epidemiology and Infection 110, 507-517.

Saarinen, U. M.\& Kajosaari, M. (1995). Breastfeeding as prophylaxis against atopic disease: prospective followup study until 17 years old. Lancet 346, 1065-1069.

Samuelsson, U., Johansson, C. \& Ludvigsson, J. (1993). Breastfeeding seems to play a marginal role in the prevention of insulin-dependent diabetes mellitus. Diabetes Research and Clinical Practice 19, $203-210$.

Saukkonen, T., Savilahti, E., Vaarala, O., Virtala, E. T., Tuomilehto, J. \& Akerblom, H. K. (1994). Children with newly diagnosed IDDM have increased levels of antibodies to bovine serum albumin but not to ovalbumin. Childhood Diabetes in Finland Study Group. Diabetes Care 17, 970-976.

Sauls, H.S. (1979). Potential effect of demographic and other variables in studies comparing morbidity of breastfed and bottle-fed infants. Pediatrics 64, 523-527.

Savilahti, E., Åkerblom, H. K., Tainio, V. M. \& Koskimies, S. (1988). Children with newly diagnosed insulindependent diabetes mellitus have increased levels of cow's milk antibodies. Diabetes Research 7, $137-140$.

Schanler, R. J. (1995). Suitability of human milk for the low-birthweight infant. Clinics in Perinatology 22, 207-222.

Sheard, N. F. (1993). Breast-feeding protects against otitis media. Nutrition Reviews 51, 275-277.

Shu, X. O., Clemens, J., Zheng, W., Ying, D. M., Ji, B. T. \& Jin, F. (1995). Infant breastfeeding and the risk of childhood lymphoma and leukaemia. International Journal of Epidemiology 24, 27-32.

Sigurs, N., Hattevig, G.\& Kjellman, B. (1992). Maternal avoidance of eggs, cow's milk, and fish during lactation: effect on allergic manifestations, skin-prick tests, and specific IgE antibodies in children at age 4 years. Pediatrics 89, 735-739.

Tainio, V.-M., Savilahti, E., Salmenpera, L., Arjomaa, P., Siimes, M. A. \& Perheentupa, J. (1988). Risk factors for infantile recurrent otitis media: atopy but not type of feeding. Pediatric Research 23, 509-512.

Takala, A. K., Eskola, J., Palmgren, J., Ronnberg, P. R., Kela, E., Rekola, P. \& Makela, P. H. (1989). Risk factors of invasive Haemophilus influenzae type b disease among children in Finland. Journal of Pediatrics 115 , $694-701$.

Taylor, B. \& Wadsworth, J. (1984). Breastfeeding and child development at five years. Developmental Medicine and Child Neurology 26, 73-80.

Teele, D. W., Klein, J. O., Rosner, B. \& Greater Boston Otitis Media Study Group (1989). Epidemiology of otitis media during the first seven years of life in children in greater Boston: a prospective, cohort study. Journal of Infectious Diseases 160, 83-94.

Temboury, M. C., Otero, A., Polanco, I. \& Arribas, E. (1994). Influence of breastfeeding on the infant's intellectual development. Journal of Pediatric Gastroenterology and Nutrition 18, 32-36.

Uauy-Dagach, R. \& Mena, P. (1995). Nutritional role of omega-3 fatty acids during the perinatal period. Clinical Perinatolog. 22, 157 - 175.

Valdes-Dapena, M. A. (1991). The phenomenon of sudden infant death syndrome and its challenges. In Sudden Infant Death Syndrome: Who Can Help and How?, pp. 3-13 [C. A. Corr, H. Fuller, C. A. Barnickol and D. M. Corr, editors]. New York: Springer.

van den Bogaard, C., van den Hoogen, H. J. M., Huygen, F. J. A. \& van Weel, C. (1991). The relationship between breastfeeding and early childhood morbidity in a general population. Family Medicine 23, 510-515.

Verge, C. F., Howard, N. J., Irwig, L., Simpson, J. M., Mackerras, D. \& Silink, M. (1994). Environmental factors in childhood IDDM. Diabetes Care 17, 1381-1389.

Virtanen, S. M. \& Aro, A. (1994). Dietary factors and the aetiology of diabetes. Annals of Medicine 26, 469-478.

Virtanen, S. M., Rasanen, L., Ylonen, K., Aro, A., Clayton, D., Langholz, B., Pitkaniemi, J., Savilahti, E., Lounamaa, R. \& Tuomilehto, J. (1993). Early introduction of dairy products associated with increased risk of IDDM in Finnish children. The Childhood Diabetes in Finland Study Group. Diabetes 42, 1786 1790.

Walterspiel, J. N., Morrow, A. L., Guerrero, M. L., Ruiz-Palacios, G. M. \& Pickering, L. K. (1994). Secretory anti-Giardia lamblia antibodies in human milk: protective effect against diarrhea. Pediatrics 93, 28 - 31.

Warner, J. O. (1980). Food allergy in fully breastfed infants. Clinical Allergy 10, 133-136.

Watson, E., Gardner, A. \& Carpenter, G. (1981). An epidemiological and sociological study of unexpected death in infancy in nine areas of Southern England. Medicine, Science and the Law 21, 78-88.

Whorwell, P. J., Holdstock. G., Whorwell, G. M. \& Wright, R. (1979). Bottle-feeding, early gastroenteritis, and inflammatory bowel disease. British Medical Journal i, 382.

Wigginton, J. M. \& Thill, P. (1993). Infant botulism: a review of the literature. Clinical Pediatrics 32, $669-674$. 
Woodward, A., Douglas, R. M., Graham, N. M. H. \& Miles, H. M. (1990). Acute respiratory illness in Adelaide children: breastfeeding modifies the effect of passive smoking. Journal of Epidemiology and Community Health 44, 224-230.

Wray, J. D. (1990). Breastfeeding: an international and historical perspective. In Infant and Child Nutrition, pp. 62-118 [F. Falkner, editor]. Caldwell, NJ: Telford Press.

Wright, A. L., Holberg, C. J., Martinez, F. D., Morgan, W. J. \& Taussig, L. M. (1989). Breast feeding and lower respiratory tract illness in the first year of life. British Medical Journal 299, 946-949.

Wright, A. L., Holberg, C. J., Taussig, L. M. \& Martinez, F. D. (1995). Relationship of infant feeding to recurrent wheezing at age 6 years. Archives of Pediatric and Adolescent Medicine 149, 758-763.

Wright, P. \& Deary, I. J. (1992). Breastfeeding and intelligence. Lancet 339, 612.

Wright, S. (1985). Atopic dermatitis and essential fatty acids: a biochemical basis for atopy? Acta DermatoVenereologica (Suppl. 114), 143-145.

Wright, S. \& Bolton, C. (1989). Breast milk fatty acids in mothers of children with atopic eczema. British Journal of Nutrition 62, 693-697.

Yellis, M. B. (1995). Human breast milk and facilitation of gastrointestinal development and maturation. Gastroenterology Nursing 18, 11-15.

Yolken, R. H., Peterson, J. A., Vonderfecht, S. L., Fouts, E. T., Midthun, K. \& Newburg, D. S. (1992). Human milk mucin inhibits rotavirus replication and prevents experimental gastroenteritis. Journal of Clinical Investigation 90, 1984-1991.

Yoon, J.-W. \& Ray, U. R. (1985). Perspectives on the role of viruses in insulin-dependent diabetes. Diabetes Care 8 (Suppl.), 39-44.

Zeiger, R. S., Heller, S., Mellon, M., O'Connor, R. \& Hamburger, R. N. (1986). Effectiveness of dietary manipulation in the prevention of food allergy in infants. Journal of Allergy and Clinical Immunology 78 , $224-238$. 